\title{
A telegeriatric service in a small rural hospital: a case study and cost minimisation analysis
}

Marloes Versleijen, (1) Melinda G Martin-Khan, (2,3) Jennifer A Whitty, (4) Anthony C Smith (3) and Leonard C Gray (2,3)

1 Economics of Consumers and Households, Wageningen University, The Netherlands 2 Centre for Research in Geriatric Medicine, The University of Queensland, Australia 3 Centre for Online Health, The University of Queensland, Australia

4 School of Pharmacy, The University of Queensland, Australia

Correspondence:

Dr. Melinda Martin-Khan,

Centre for Research in Geriatric Medicine,

Building 33, Level 2, Princess Alexandra Hospital,

Ipswich Road, Woolloongabba, Queensland, 4120, Australia.

(Email: m.martinkhan@uq.edu.au

Running head: Telegeriatrics

Disclosure statement:

Competing interests: CeGA Online software is owned and distributed by Uniquest, the commercialisation arm of The University of Queensland, Australia. 


\section{Summary}

Small hospitals in rural areas usually have an insufficient caseload of frail old people to justify the regular presence of a geriatrician. This study examined the costs of providing a telegeriatric service by videoconference in a rural hospital, compared to the costs of a visiting geriatrician that travels to undertake in-person consultations. A cost-minimisation analysis was undertaken to compare the costs of the telegeriatric service model with the costs of a visiting geriatrician service model. A recently established telegeriatric service at Warwick Hospital was used as a case study. In the base case model (assuming four patients per round

and a round-trip travel distance of 312 kilometres) an estimated \$AUl31 per patient consultation can be saved in favour of the telegeriatric service model. Key drivers of costs are the number of patients per round and the travel distance and time in the visiting geriatrician model. At a workload of four patients per round, it is less expensive to conduct a telegeriatric service rather than a visiting geriatrician service, when the round-trip travel time exceeds 76 minutes. Even under quite conservative assumptions, a telegeriatric service offers an economically feasible approach to the delivery of specialist geriatric assessment in rural and remote settings.

\section{Introduction}

Comprehensive geriatric assessment (CGA) is a "multidimensional interdisciplinary diagnostic process focused on determining a frail older person's medical, psychological and functional capability in order to develop a coordinated and integrated plan for treatment and long term follow up" (1). Geriatricians and specialist nurses are central to this process, with important contributions made by social and allied health workers. Reviews report beneficial outcomes for patients treated with CGA compared to usual care (2-5), with results being in favour of designated geriatric wards rather than visiting multidisciplinary teams $(2,4)$.

Small hospitals in rural areas often have an insufficiently large caseload of frail old people to justify the regular presence of a geriatrician in the town. As a result, geriatricians travel to rural hospitals to enable in-person consultations. This limits consultations to long stay patients, and prevents the daily/weekly contribution to the multi-disciplinary process that characterises geriatric and rehabilitation units in metropolitan and regional centres. In most jurisdictions, geriatricians are in short supply, and the likelihood of routine visits to small hospitals is low (6).

The application of telemedicine in geriatrics is relatively new and sound evidence of benefits and cost-effectiveness is still lacking (7). Although no evidence is available for this particular service model in terms of patient outcomes, a pilot in a similar setting showed promising results (8). Assessing telemedicine applications and their required resources is a challenge (9). A review of economic analyses on real-time video communication states that telemedicine can be cost-effective for rural health care, depending upon the specific setting and health service delivery model (10).

Previously, we developed a telehealth service model which incorporates a combination of asynchronous and video-conference (VC) strategies, to support a geriatric and rehabilitation inpatient service in a large regional hospital which was unable to recruit a geriatrician (11). This paper evaluates the deployment of a similar model to small rural hospitals where the challenge of lower numbers of older inpatients requiring geriatric consultation and subacute 
services could impact sustainability. This model is currently deployed in five small rural hospitals in southern Queensland, which range in distance from Brisbane of $150 \mathrm{~km}$ to 500 $\mathrm{km}$, and service capacity of between 13 and 60 beds.

In this study, we selected one of these sites - the first to be established and thus with the most stable operation - to conduct a cost-minimisation analysis.

\section{Methods}

A cost-minisation analysis was undertaken to compare the costs of the telegeriatric service model to the costs of a visiting geriatrician service model. A health service perspective was taken. We assumed that both service models are equally effective in terms of efficacy and health outcomes. Formal ethics approval was not required.

\section{The study site}

Warwick is located in the Southern Downs of South East Queensland and has a population of

around 13,000 people (12). The Warwick Hospital is a 60-bed acute care facility, with an additional 40-bed high care residential aged care facility situated on the same campus. Older patients are admitted to a general ward. In the majority of cases, older patients without major medical and surgical problems are managed on location in Warwick. Geriatrician expertise is available at Princess Alexandra Hospital (PAH) in Brisbane $(155 \mathrm{~km})$ but prior to the establishment of the telehealth service described here, there was no on-location geriatrician service.

Aggregated hospital data on Warwick Hospital were requested from the Queensland Hospital

Admitted Patient Data Collection (QHAPDC) at the Health Statistics Unit. In 2011-12, prior to the commencement of the geriatric telehealth service, over 4,000 episodes and almost 15,000 patient days were recorded at Warwick Hospital. Persons aged 65 years and over accounted for $66.3 \%$ of patient days, with persons aged 85 years and over accounting for $22.3 \%$ of patient days.

\section{Intervention}

In August 2012, a telegeriatric service was established at Warwick Hospital by the PAH Telehealth Centre, and was in routine operation at the time of writing. The service is

provided by a geriatrician through the PAH Telehealth Centre, where the telemedicine facilities are located and the clinical coordination, medical administration, technical and software support for the telegeriatric rounds are provided.

Telegeriatric rounds are organised routinely once per week. A geriatrician attends the rounds from a telemedicine studio. At the Warwick end, a mobile videoconference system is used to connect with the specialist. A nurse assessor at Warwick Hospital identifies eligible patients (those considered likely to require an extended hospital stay due to geriatric syndromes, recent functional decline or psychosocial issues). The nurse assessor "prepares" cases for

consultation by conducting a structured assessment using the CeGA Online clinical decision support system(6). This information, and profiles generated by the system, are available to the geriatrician prior to commencement of rounds.

The weekly rounds are organised in three components, which broadly emulate a conventional patient round: pre-discussion in which each patient is discussed by the nurse assessor and the PAH geriatrician, sometimes accompanied by a house physician at the Warwick end; and a ward round in which the geriatrician interacts with the patients at the bedside, hosted by the 
nurse assessor. During the ward rounds a physician at Warwick can be consulted to execute elements of the physical examination which cannot be performed by VC; the round ends with a multidisciplinary team meeting, which involves a Warwick-based physiotherapist, occupational therapist and social worker, along with the nurse assessor and PAH geriatrician.

The service is supported by the clinical decision support system - 'CeGA Online' which is a web-based software application based on the interRAI Acute Assessment (AC) system (6). The interRAI AC is a comprehensive assessment system developed for geriatric assessment in acute care hospitals $(13,14)$. This system is based on clinical observations and a suite of derivative applications to support diagnostic and risk screening, care planning and monitoring of progress over time(15). The geriatrician also has access to the imaging and pathology results, online. All information is available on the desktop in front of the geriatrician (Figure $1)$.

\section{$<$ Insert Figure 1 about here >}

\section{Comparator}

The comparator was a theoretical visiting geriatrician service model. It was assumed that a geriatrician travelled weekly by car from the PAH to Warwick Hospital. The service models are similar in function, but different in regards to transport requirements and communication methods.

\section{Outcome}

The unit of evaluation was cost per patient per round, and this was compared for the two service models.

\section{Resources and costs}

The costs were divided into fixed costs, which did not vary with the number of patients, and variable costs, which increase as the number of patients increase. Fixed capital costs include one-time initial investments required for establishing the telegeriatric service (which were annuitized assuming a three year equipment lifespan), and recurrent non-investment costs. Resources were divided into required resources for PAH (studio) and Warwick (remote) Hospitals. All costs are expressed in 2013 Australian Dollars (AUD) per annum. Costs were

rounded to the nearest dollar value, unless otherwise specified. Common costs for both service models, e.g. medical supplies, room rental and hospital overhead costs were not included. The maximum capacity for one round was set at twenty patients.

\section{Telegeriatric service model.}

Information on required resources and estimated costs for the telegeriatric service model were obtained from The University of Queensland Centre for Online Health. At the studio end, the service is provided from a telemedicine studio at the PAH Telehealth Centre, for four hours per week. It was assumed that at other times, the videoconference room was in constant use,

with a total operational time of 40 hours a week. At the remote end no studio is required as the service is facilitated by a mobile $\mathrm{VC}$ device. At the time of the study, the VC equipment at Warwick Hospital was used solely for the telegeriatric service (however, at the time of publication, this was no longer the case). In the current study fixed costs are corresponding to a portion of total operational time that resources are used for the service (studio end: $10 \%$, remote end: $100 \%)$. 
Variable costs include staff resources, including geriatrician, nurse assessor and allied health, and support resources, including round coordination, medical administration, technical and software support. Physician resources at the remote end were excluded, as physicians are only consulted "on the spot" occasionally for short periods of time, and this also occurs during conventional in person visits. Timing sheets measured staff resources for the telegeriatric rounds. During three subsequent telegeriatric rounds per-patient-time was

measured for the pre-discussion, time at the patients' bed side (ward round) and the team meeting. Time required for geriatrician preparations and after-round report documentation was estimated based on a geriatrician's experiences. A nurse assessor at Warwick Hospital recorded time needed for round preparations, including CGA Online data collection and data entry, for a period of one week. Annual staff costs were calculated by multiplying mean time per patient by the total number of patients per annum and the hourly cost of the corresponding staff resource. Nurse assessor preparation time was only required (and thus included) for new patients.

\section{Visiting geriatrician service model.}

Timing data for the theoretical visiting geriatrician model was modelled on data from a previous study on a similar service(11). Travel resources were required for the geriatrician travelling from PAH to Warwick Hospital. Two types of travel resources were distinguished, travel distance and travel time. Travel distance costs were calculated by multiplying the number of kilometres for a round-trip by a rate per kilometre (A $\$ 0.60)$. Travel distance was obtained from Google maps and converted to travel time at 80 kilometres per hour. Travel time costs represent the forgone geriatrician employment costs associated with clinical time lost. These opportunity costs were calculated by multiplying the travel time for a round-trip

by the hourly fee of the geriatrician.

\section{Sensitivity analysis}

One-way sensitivity analyses were undertaken to identify key drivers of costs. All parameters in the model were varied individually according to low and high input values, while holding all other aspects of the model constant. To determine low and high input values, base case values were decreased or increased by $66.67 \%$ of their base value. Subsequently, identified key drivers were investigated in two-way sensitivity analyses by varying two parameters over a plausible range.

\section{Results}

Required resources and assigned unit costs for both service models are displayed in Table 1.

\section{< Insert Tablelabouthere >}

The cost comparison between the telegeriatric and the visiting geriatrician service model are displayed in Table 2. Patient data was taken from telegeriatric rounds in Warwick (August

2012-March 2013). During this period there were 35 patients assessed by VC (patient average length of stay 17 days; average length of time from admission to initial assessment by VC: 5 days). A typical telegeriatric round at Warwick consisted of four patients, including two new patients. The staff resources included one geriatrician, one nurse assessor and four allied health workers. The average duration of a round, excluding preparation time and after-round report preparation, was 1 hour and 53 minutes.

$<$ Insert Table 2 about here > 
For the telegeriatric service, the mean time required per patient per round was 4.9 minutes [range 0.5-14.0, SD 4.2] for the pre-discussion, 15.2 minutes [range 4.4-45.6, SD 11.6] for the ward round, and 6.1 minutes [range 2.6-11.8, SD 3.0] for the team meeting. Total mean time per patient was 26.8 minutes [range 13.4-68.7, SD 16.1]. A difference was observed in mean time per patient for new and review patients, 35.8 minutes [range 21.6-68.7, SD 22.1]

and 20.8 minutes [range 13.4-31.8, SD 7.9] respectively. Based on a geriatrician's experiences the estimated time needed for preparing the rounds is on average 15 minutes per patient. In addition, an estimated total time of 20 minutes is required for report documentation after the round. Assuming a typical round of four patients, the total time per round needed for geriatrician preparation and report documentation is 80 minutes. The nurse assessor at Warwick Hospital required on average 187 minutes [range 150-210, SD 28] per new patient for case preparation. Of this time, on average 67 minutes [range $60-90$, SD 15] were spent on data collection and on average 120 minutes [range 90-150, SD 24] on data entry into CGA Online. Because of the small scale character of the round, all supporting

tasks were executed by one person, and required an estimated 45 minutes per week. The estimated annual cost of the telegeriatric service is $\$ 73,685$, which equates to $\$ 354$ per patient perround.

The travel distance for the visiting geriatrician is 312 kilometre for the round-trip, which takes approximately 234 minutes. Annual travel costs are $\$ 50,294$. Of these travel costs $\$ 40,560$ are travel time costs and $\$ 9,734$ are travel distance costs. The estimated annual cost of the visiting geriatrician service model is $\$ 101,025$, which equates $\$ 486$ per patient per round. Of these costs, approximately $40 \%$ are allocated for travel purposes.

Table 3 shows the low and high input values that were tested with one-way sensitivity analyses. Parameters that did not affect the outcome of the model, as they are assumed to be at the same level for both service models, were excluded (CGA Online user fees, staff training, geriatrician and nurse preparation and after-round report documentation). The results of the sensitivity analyses are displayed in the tornado chart in Figure 2. The vertical axis in the figure represents the base case cost-saving of $\$ 131$ per patient per round. The most important driver of costs in the current model is the number of patients per round. Other key drivers are mostly related to the geriatrician, including travel distance, travel time,

geriatrician's hourly fee and annual geriatrician's resources. The latter includes round time and preparation time. Travel time and travel distance are not independent; however, in this model they had a similar impact on comparative costs. However, when applying this model to other settings travel time may be a more relevant variable than travel distance, as speed per kilometre might differ greatly between urban and rural areas.

$<$ Insert Table 3 about here

$<$ Insert Figure 2 about here >

In the base case, assuming four patients per round, the telegeriatric service is cost-saving when travel time for a round-trip exceeds 76 minutes. Results of the two-way sensitivity analysis are displayed in Figure 3. When varying travel time and number of patients per round simultaneously while holding all other aspects of the model constant, at a low estimate of one patient per round the break-even travel time is 48 minutes. At a high estimate of seven patients per round the break-even travel time is 105 minutes. 


\section{$<$ Insert Figure 3 about here}

\section{Discussion}

This study demonstrates that a telegeriatric service is a feasible and cost saving service in the rural health service setting; helping hospital administrators in decision-making to improve access to specialist geriatric services whilst using healthcare resources more efficiently. This

study has global applicability(16).

The current study identified the number of patients per round as a key driver of costs. Decreasing the number of patients per round decreases the break-even travel time to justify a telegeriatric service. However, with the observed mean number of four patients assessed per telegeriatric round, the telegeriatric service remained cost saving for round trip travel times as low as 76 minutes.

Despite substantial capital investment, in the base case model an estimated \$131 per patient per round can be saved by providing the geriatric service through VC. If the VC equipment were to be used by one additional specialty at the remote end, the break-even round-trip travel time is 38 minutes at four patients per round. With each additional speciality the VC service model become more economically viable.

The current cost-minimisation analysis assumes that patients would have access to a geriatrician in either model of care, and that both service models result in similar outcomes. Reviews on telemedicine identify a need for robust studies on costs linked to patient outcomes $(9,10,17-21)$ It is possible (but unproven) that face to face models may offer better

outcomes; however, it is also a reality that face to face service delivery is unattainable for all patients. In such a scenario, telegeriatric services may well provide preferable outcomes to the possibly more realistic scenario of a comparator of no specialist service at all.

\section{Limitations.}

We acknowledge that while costs for staff have been calculated by the minute, staff are in fact employed on a contract basis which doesn't take into account such small variations in utilisation, therefore the business case needs to take into account the full nurse assessor role, which involves other duties. The timing estimates may be over-estimated in this study due to

the experience level of personnel involved (experienced geriatricians estimated preparation and report writing; inexperienced nurses completing nurse assessments and data entry), and the small number of cases used in the estimates for this study. Finally, the costs associated with the visiting geriatrician are assumptions which are as closely aligned to the experience at the PAH as possible. Given that the telehealth model (the intervention) is based on actual data, this paper provides a useful guide for the reader to apply a cost comparison to an existing in-person service.

\section{Conclusion}

The current study indicates that a telegeriatric service offers an economically feasible approach to the delivery of specialist geriatric assessment in a rural and remote setting. The outcomes of this study are especially of interest to rural and remote hospitals that cannot justify a designated geriatric unit or the fulltime presence of a geriatrician because of an insufficient caseload of frail older people. The proposed innovative model of health service delivery provides access to geriatric expertise in settings where geriatric services would not be available otherwise. 


\section{Acknowledgements}

We thank Chrissie Norton for her advice on the financial model and telehealth cost estimates.

We appreciate the support and efforts of the Metro South Hospital and Health Service and the

Darling Downs Hospital and Health Service in Queensland; and thank the PAH Telehealth Centre for their role in coordinating the telegeriatric services. This research was conducted with the support of the Centre of Research Excellence (CRE) in Telehealth funded by NHMRC (grant ID: APP1061183). Dr. MG Martin-Khan is supported with a CRE in Telehealth (Aged Care) post-doctoral fellowship. 
Table 1 Required resources and assigned unit costs for the telegeriatric and the visiting geriatrician service model, by studio and remote end (Total costs)

\begin{tabular}{|c|c|c|}
\hline TELEGERIATRIC SERVICE MODEL & Studio end & Remote end \\
\hline \multicolumn{3}{|l|}{ FIXED CAPITAL COSTS (A) } \\
\hline Videoconferencing equipment (B) & 20,000 & 25,000 \\
\hline Set-up videoconferencing equipment, incl. site visits (C) & 0 & 5,000 \\
\hline Telecommunication line installation, $2 \mathrm{Wi}$-Fi points & 2,800 & 2,800 \\
\hline Studio fit-out (D) & $15 \mathrm{sqm}$ a $\$ 100 / \mathrm{sqm}$ & n.a. \\
\hline \multicolumn{3}{|l|}{ OTHER FIXED COSTS } \\
\hline Studio office lease (D) & 15 sqm a & n.a. \\
\hline Telecommunication line user fees & $\$ 200 /$ month & \$200/month \\
\hline CGA Online user fees & $\$ 5,000 / 3$ years & $\$ 5,000 / 3$ \\
\hline Staff training CGA Online (E) & $\$ 400$ & $\$ 3,000$ \\
\hline \multicolumn{3}{|l|}{ VARIABLE COSTS } \\
\hline \multicolumn{3}{|l|}{ Staff resources: } \\
\hline \multicolumn{3}{|l|}{$\begin{array}{l}\text { Geriatrician preparation and after-round report documentation CGA } \\
\text { Online }\end{array}$} \\
\hline Geriatrician round time & $\$ 200 / \mathrm{h}$ & n.a. \\
\hline Clinical nurse preparation CGA Online $(\mathrm{F})$ & n.a. & $\$ 40 / \mathrm{h}$ \\
\hline Clinical nurse round time & n.a. & $\$ 40 / \mathrm{h}$ \\
\hline Allied health multidisciplinary team meeting time & n.a. & $\$ 40 / \mathrm{h}$ \\
\hline \multicolumn{3}{|l|}{ Support resources: } \\
\hline Technician's hourly fee & $\$ 40 / \mathrm{h}$ & n.a. \\
\hline Software support's hourly fee & $\$ 40 / \mathrm{h}$ & n.a. \\
\hline Coordinator's hourly fee & $\$ 35 / \mathrm{h}$ & n.a. \\
\hline Administrator's hourly fee & $\$ 30 / \mathrm{h}$ & n.a. \\
\hline VISITING GERIATRICIAN SERVICE MODEL & Studio end & Remote end \\
\hline $\begin{array}{l}\text { FIXED CAPITAL COSTS } \\
\text { NA. }\end{array}$ & FIXED CAPITAL COSTS & \\
\hline \multicolumn{3}{|l|}{ OTHER FIXED COSTS } \\
\hline CGA Online user fees & $\$ 5,000 / 3$ years & $\$ 5,000 / 3$ \\
\hline Staff training CGA Online (E) & $\$ 400$ & years \\
\hline \multicolumn{3}{|l|}{ VARIABLE COSTS } \\
\hline \multicolumn{3}{|l|}{ Staff resources: } \\
\hline $\begin{array}{l}\text { Geriatrician preparation and after-round report documentation CGA } \\
\text { Online }\end{array}$ & $\$ 200 / \mathrm{h}$ & n.a. \\
\hline Geriatrician round time & $\$ 200 / \mathrm{h}$ & n.a. \\
\hline Clinical nurse preparation CGA Online $(\mathrm{F})$ & n.a. & $\$ 40 / \mathrm{h}$ \\
\hline Clinical nurse round time & n.a. & $\$ 40 / \mathrm{h}$ \\
\hline Allied health multidisciplinary team meeting time & n.a. & $\$ 40 / \mathrm{h}$ \\
\hline \multicolumn{3}{|l|}{ Travel resources: } \\
\hline Geriatrician travel distance round-trip, km (G) & 312 & n.a. \\
\hline Geriatrician travel time round-trip, $\min (\mathrm{H})$ & 234 & n.a. \\
\hline Rate per km (I) & 0.60 & n.a. \\
\hline
\end{tabular}


(A) All capital costs are annuitized assuming an expected lifespan of 3 years, a depreciation rate of $25 \% \&$ a resale value of 0 .

(B) Fixed device at studio end, mobile device at remote end.

(C) No site visits needed at studio end.

(D) No studio at remote end: mobile videoconferencing equipment.

(E) Studio end: 2 hours a $\$ 200 / \mathrm{h}$ (geriatrician hourly fee). Remote end: total price for a 2-day training.

(F) Nurse preparation in CGA Online only required in case of a new patient.

(G) Source: Google maps.

(H) Travel distance is converted into travel time assuming a travel speed of $80 \mathrm{~km} / \mathrm{h}$.

(I) Source: (20) 
Table 2: Cost comparison of a telegeriatric and a visiting geriatrician service model, by studio and remote end

\begin{tabular}{|c|c|c|c|c|c|}
\hline & $\begin{array}{r}\text { Annual cost } \\
\text { servic }\end{array}$ & $\begin{array}{l}\text { telegeriatric } \\
\text { model }\end{array}$ & $\begin{array}{l}\text { Annual co } \\
\text { geriatrician }\end{array}$ & $\begin{array}{l}\text { ts visiting } \\
\text { rvice model }\end{array}$ & $\begin{array}{l}\text { Difference } \\
\text { Difrics }\end{array}$ \\
\hline & Studio end & Remote end & Studio end & Remote end & \\
\hline FIXED CAPITAL COSTS (A) & 8,100 & 10,933 & 0 & 0 & $-19,033$ \\
\hline Annuitized videoconferencing equipment & 6,667 & 10,000 & 0 & 0 & $-16,667$ \\
\hline Annuitized telecommunication line installation & 933 & 933 & 0 & 0 & $-1,867$ \\
\hline Annuitized studio fit-out & 500 & 0 & 0 & 0 & -500 \\
\hline OTHER FIXED COSTS & 10,467 & 7,067 & 2,067 & 4,667 & $-10,800$ \\
\hline Studio office lease & 6,000 & 0 & 0 & 0 & $-6,000$ \\
\hline Telecommunication line user fees & 2,400 & 2,400 & 0 & 0 & $-4,800$ \\
\hline CGA Online user fees & 1,667 & 1,667 & 1,667 & 1,667 & 0 \\
\hline Staff training CGA Online & 400 & 3,000 & 400 & 3,000 & 0 \\
\hline TOTAL fixed costs (B) & $\begin{array}{r}1,857 \\
19 \\
\end{array}$ & 18,000 & $\begin{array}{r}207 \\
4,\end{array}$ & 4,667 & $-14,983$ \\
\hline VARIABLES COSTS & & & & & \\
\hline Staff resources $(C)$ & 32,448 & 20,015 & 27,179 & 18,678 & $-6,606$ \\
\hline Geriatrician costs & 32,448 & 0 & 27,179 & 0 & $-5,269$ \\
\hline Nurse costs & 0 & 16,682 & 0 & 15,628 & $-1,054$ \\
\hline Allied health costs & 0 & 3,334 & 0 & 3,051 & -283 \\
\hline Support resources $(D)$ & 1,365 & 0 & 0 & 0 & $-1,365$ \\
\hline Technician costs & 0 & 0 & 0 & 0 & 0 \\
\hline Software support costs & 0 & 0 & 0 & 0 & 0 \\
\hline Clinical coordination costs & 1,365 & 0 & 0 & 0 & $-1,365$ \\
\hline Medical administration costs & 0 & 0 & 0 & 0 & 0 \\
\hline Travel resources & 0 & 0 & 50,294 & 0 & 50,294 \\
\hline Travel distance costs & 0 & 0 & 9,734 & 0 & 9,734 \\
\hline Travel time costs & 0 & 0 & 40,560 & 0 & 40,560 \\
\hline TOTAL variable costs & $\begin{array}{r}33,813 \\
53\end{array}$ & 20,015 & $\begin{array}{r}77,473 \\
96\end{array}$ & 18,678 & 42,323 \\
\hline TOTAL fixed \& variable costs & $\begin{array}{r}35,670 \\
73\end{array}$ & $\begin{array}{rr} & 38,015 \\
85 & \\
\end{array}$ & $\begin{array}{r}77,680 \\
101\end{array}$ & $\begin{array}{rr} & 23,345 \\
& \\
\end{array}$ & 27,340 \\
\hline $\begin{array}{l}\text { COST PER PATIENT ( } 208 \text { patients) } \\
\text { (4 patients per round, of which } 2 \text { are new) }\end{array}$ & & & & & 131 \\
\hline
\end{tabular}

Active assumptions: 4 patients a round of which 2 new patients, 1 round a week \& a round-trip travel distance of $312 \mathrm{~km}$

(A) All capital costs are annuitized assuming an expected lifespan of 3 years, a depreciation rate of $25 \%$ and a resale value of 0 .

(B) Fixed costs are corresponding to portion of total operational time that resources are used for the service (studio end: $10 \%$, remote end: $100 \%)$.

(C) Based on one geriatrician, one nurse assessor and four allied health workers. House physician excluded.

(D) All supporting tasks were executed by one person (coordinator), and required an estimated 45 minutes per week. 
Table 3: Low and high input values for one-way sensitivity analyses

\begin{tabular}{|c|c|c|c|}
\hline & & \multicolumn{2}{|c|}{ Input values (A) } \\
\hline & Base case & Low & High \\
\hline Total number of patients per round (B) [n/wk] & 4 & 1 & 7 \\
\hline Videoconferencing equipment (s) [\$] & 20,000 & 6,667 & 33,333 \\
\hline Videoconferencing equipment (r) [\$] & 25,000 & 8,333 & 41,667 \\
\hline Set-up videoconferencing equipment (r) [\$] & 5,000 & 1,667 & 8,333 \\
\hline Telecommunication line installation (s) [\$] & 2,800 & 933 & 4,667 \\
\hline Telecommunication line installation (r) [\$] & 2,800 & 933 & 4,667 \\
\hline Studio office lease (s) [\$] & 6,000 & 2,000 & 10,000 \\
\hline Telecommunication line user fees (s) [\$] & 2,400 & 800 & 4,000 \\
\hline Telecommunication line user fees $(r)[\$]$ & 2,400 & 800 & 4,000 \\
\hline Share of fixed costs $(\mathrm{s})[\$]$ & 0.1 & 0.0 & 0.2 \\
\hline Share of fixed costs $(r)[\$]$ & 1.0 & 0.3 & 1.7 \\
\hline Geriatrician's hourly fee $[\$ / \mathrm{hr}]$ & 200 & 67 & 333 \\
\hline Annual geriatrician resources (telegeriatrics) [\$/yr] & 9,734 & 3.245 & 16,224 \\
\hline Annual geriatrician resources (visiting) $[\$ / y r]$ & 8,154 & 2.718 & 13,589 \\
\hline Clinical nurse hourly fee [ $\$ / \mathrm{hr}]$ & 40 & 13 & 67 \\
\hline Annual nurse resources (telegeriatrics) $[\$ / \mathrm{yr}]$ & 25,022 & 8,341 & 41,704 \\
\hline Annual nurse resources (visiting) $[\$ / y r]$ & 23,442 & 7,814 & 39,069 \\
\hline Allied health hourly fee $[\$ / h r]$ & 40 & 13 & 67 \\
\hline Annual allied health resources (telegeriatrics) [\$/yr] & 5,000 & 1,667 & 8,334 \\
\hline Annual allied health resources (visiting) [\$/yr] & 4,576 & 1,525 & 7,627 \\
\hline Coordinator's hourly fee $[\$ / \mathrm{hr}]$ & 35 & 12 & 58 \\
\hline Annual coordinator resources $[\$ / \mathrm{yr}]$ & 39 & 13 & 65 \\
\hline Geriatrician travel distance round-trip [km/wk] & 312 & 104 & 520 \\
\hline Geriatrician travel time round-trip [min/wk] & 234 & 78 & 390 \\
\hline Rate per $\mathrm{km}[\mathrm{hr} / \mathrm{km}]$ & 0.60 & 0.20 & 1.00 \\
\hline Mean round time per patient (telegeriatrics) $[\mathrm{min} / \mathrm{n}]$ & 26.8 & 8.9 & 44.7 \\
\hline Mean team meeting time per patient (telegeriatrics) $[\mathrm{min} / \mathrm{n}]$ & 6.0 & 2.0 & 10.0 \\
\hline Mean round time per patient (visiting) [min/n] & 19.2 & 6.4 & 32.0 \\
\hline Mean team meeting time per patient (visiting) $[\mathrm{min} / \mathrm{n}]$ & 5.5 & 1.8 & 9.2 \\
\hline
\end{tabular}

(s): studio end

(A): Base case values were decreased and increased by $66.67 \%$.

(B) Low input: 1 new, 0 review patients. High input: 2 new, 5 review patients. 
Figure 1: Videoconferencing with a patient in hospital (Remote site)

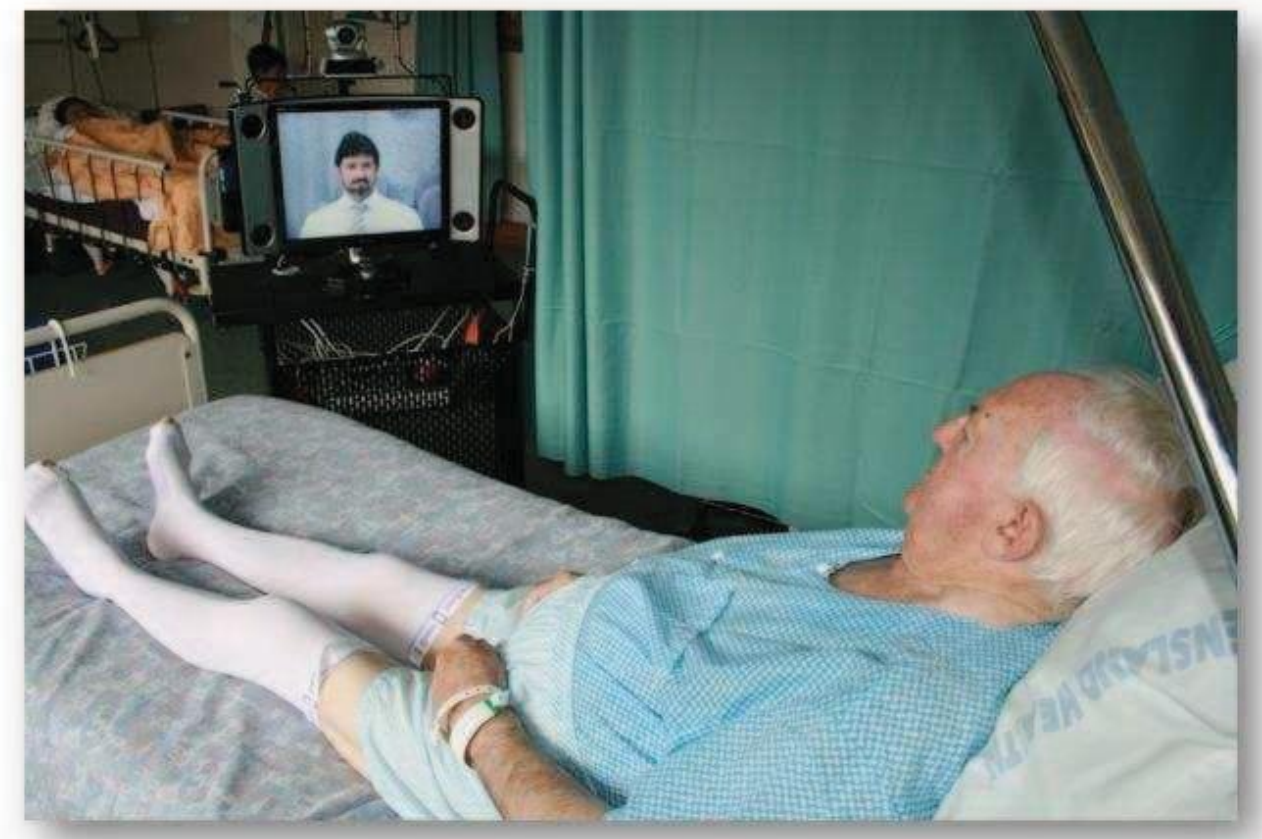


Figure 2: Cost-difference per patient per round between telegeriatric and visiting service model, for low and high input variables

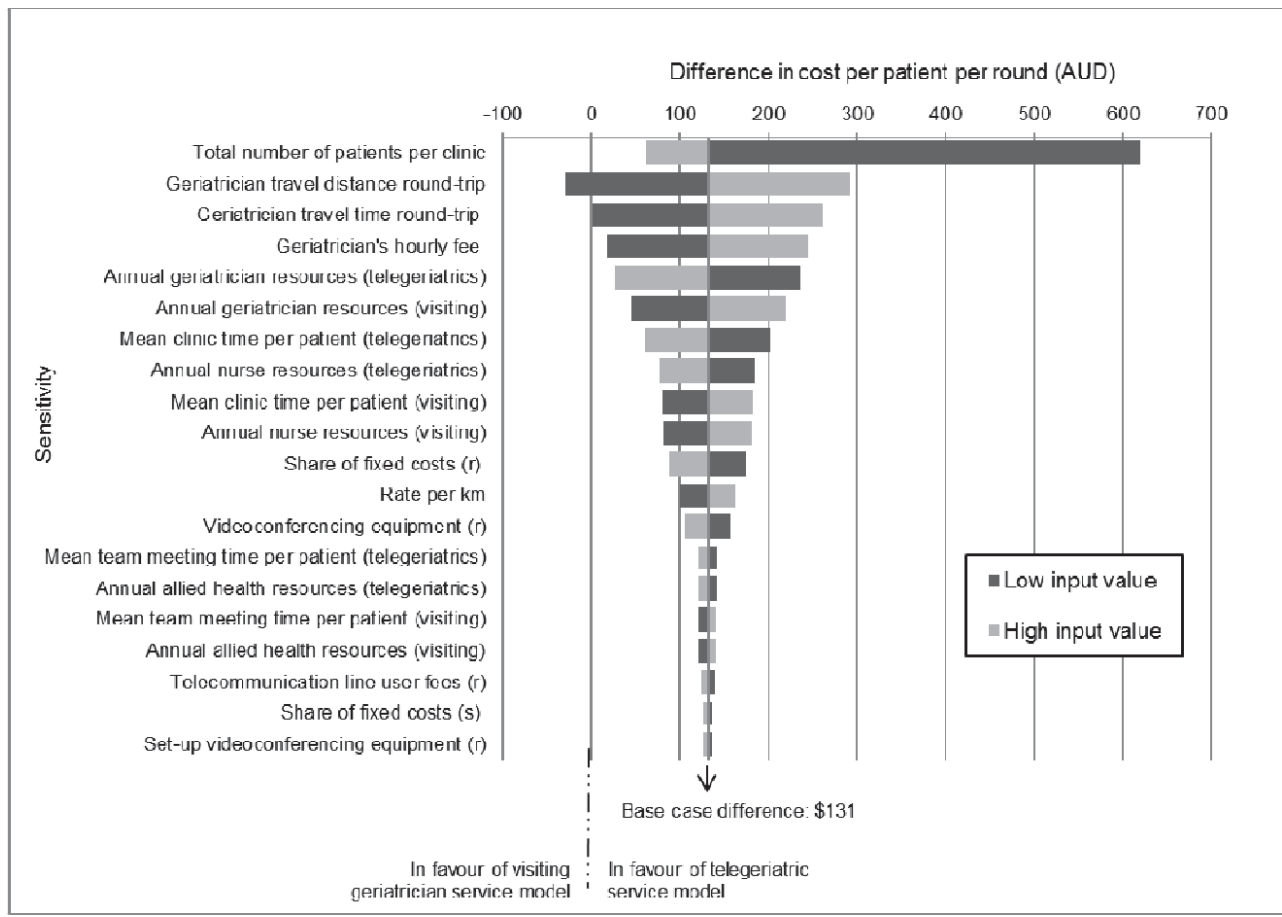

(s): studio end

(r) 
Figure 3: Cost-difference per patient per round between telegeriatric and visiting service model: number of patients per round versus geriatrician travel time

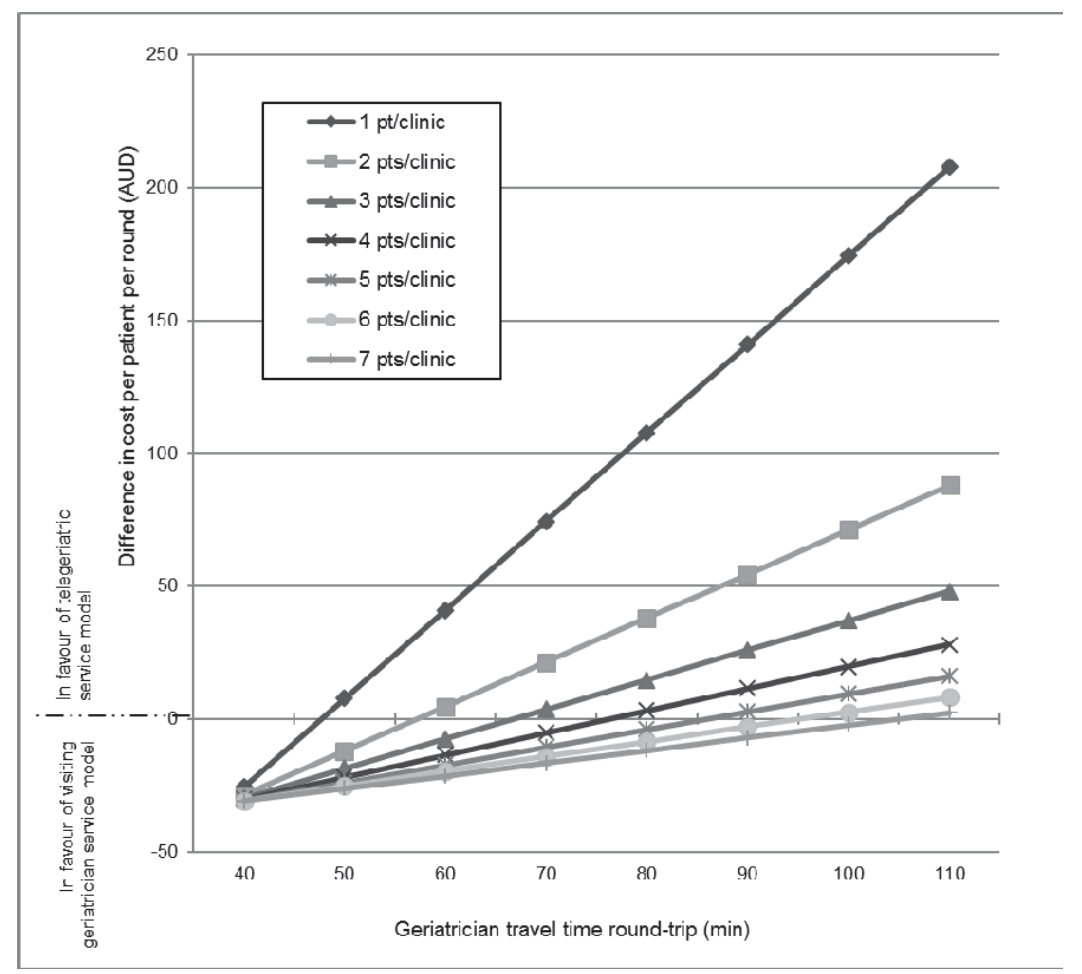


References

Rubenstein L, Stuck A, Siu A, Wieland D. Impacts of geriatric evaluation and management programs on defined outcomes: overview of the evidence. Journal of the American Geriatrics Society. 1991;39(S1):8S-16S.

2. Ellis G, Langhorne P. Comprehensive geriatric assessment for older hospital patients. British medical bulletin. 2005;71(1):45-59.

3. Stuck AE, Siu AL, Wieland GD, Rubenstein L, Adams J. Comprehensive geriatric assessment: a meta-analysis of controlled trials. The Lancet. 1993;342(8878):1032-6.

4. Ellis G, Whitehead MA, Robinson D, O'Neill D, Langhorne P. Comprehensive geriatric assessment for older adults admitted to hospital: meta-analysis of randomised controlled trials. Bmj. 2011;343:d6553.

5. Baztán JJ, Suárez-García FM, López-Arrieta J, Rodríguez-Mañas L, Rodríguez-Artalejo

F. Effectiveness of acute geriatric units on functional decline, living at home, and case fatality among older patients admitted to hospital for acute medical disorders: metaanalysis. Bmj. 2009;338:b50.

6. Gray L, Moore K, Smith R, Dorevitch M. Supply of inpatient geriatric medical services in Australia. Internal medicine journal. 2007;37(4):270-3.

7. Brignell M, Wootton R, Gray L. The application of telemedicine to geriatric medicine.

Age and Ageing. 2007;36(4):369-74.

8. Dakin L, Cutler A, Wright O, Martin-Khan M, Varghese P, Gray L. Reliability of online geriatric consultation triage decisions: a pilot study. Australasian journal on ageing.

2011;30(4):239-40.

9. Hailey D. The need for cost-effectiveness studies in telemedicine. Journal of telemedicine and telecare. 2005;11(8):379-83.

10. Wade VA, Karnon J, Elshaug AG, Hiller JE. A systematic review of economic analyses of telehealth services using real time video communication. BMC health services research. 2010;10(1):233.

11. Gray LC, Wright OR, Cutler AJ, Scuffham PA, Wootton R. Geriatric ward rounds by video conference: a solution for rural hospitals. Medical Journal of Australia.

2009;191(11):605.

12. Office of Economic and Statistical Research. Demographic Profile of Darling DownsfMaranoa Area, 2009. The State of Queensland Government (Queensland Treasury)

2009.

13. Gray LC, Berg K, Fries BE, Henrard J-C, Hirdes JP, Steel K, et al. Sharing clinical information across care settings: the birth of an integrated assessment system. BMC Health

Services Research. 2009;9(1):71.

14. Gray LC, Bernabei R, Berg K, Finne-Soveri H, Fries BE, Hirdes JP, et al. Standardizing assessment of elderly people in acute care: the interRAI Acute Care instrument. Journal of the American Geriatrics Society. 2008;56(3):536-41. 
15. Gray L, Arino-Blasco S, Berg K, Bula C, Gambassi G, Heckman G, et al. interRAl clinical and management applications manual: for use with the interRAI Acute Care Assessment Instrument Version 9.1. Washington, DC: interRAl; 2013. pp. 75 p.

16. Peterson LE, Bazemore A, Bragg EJ, Xierali I, Warshaw GA. Rural-urban distribution of the US geriatrics physician workforce. Journal of the American Geriatrics Society. 2011;59(4):699-703.

17. Hailey D, Roine R, Ohinmaa A. Systematic review of evidence for the benefits of telemedicine. Journal of telemedicine and telecare. 2002;8(suppl 1):1-7.

18. Ekeland AG, Bowes A, Flottorp S. Effectiveness of telemedicine: a systematic review of reviews. International journal of medical informatics. 2010;79(11):736-71.

19. Dávalos ME, French MT, Burdick AE, Simmons SC. Economic evaluation of telemedicine: review of the literature and research guidelines for benefit-cost analysis. Telemedicine and e-Health. 2009;15(10):933-48.

20. Armfield NR, Edirippulige SK, Bradford N, Smith AC. Telemedicine-is the cart being put before the horse. Med J Aust. 2014;200(9):530-3.

21. Edirippulige S, Martin-Khan M, Beattie E, Smith AC, Gray LC. A systematic review of telemedicine services for residents in long term care facilities. Journal of telemedicine and telecare. 2013;19(3):127-32. 